\title{
THE INFLUENCE OF EELGRASS (ZOSTERA MARINA L.) ON THE ENVIRONMENTAL FACTORS AND THE MICROBIAL COMMUNITIES IN SEDIMENT FROM SHUANGDAO BAY OF CHINA
}

\author{
LV, X. F. - YU, P. -WANG, X. L. - LI, Y. C.* \\ Marine College, Shandong University, Wenhua Xi Road 180, Weihai, Shandong, China \\ *Corresponding author \\ e-mail: li_yuchun@sdu.edu.cn; phone: +86-135-6215-7118; fax: +86-631-568-8303
}

(Received 1t Mar 2019; accepted 21 $1^{\text {st }}$ May 2019)

\begin{abstract}
Zostera marina is a perennial seagrass that is widespread on temperate coasts around the world. Some studies have showed that the presence of Z. marina in marine environments influences the microbial communities in sediment collected from Shuangdao Bay of China. To investigate the impact of Z. marina, the environmental factors and microbial communities in sediments collected in the eelgrass beds and adjacent unvegetated area, were examined. Several environmental factors and microbial communities composition differed significantly between the two areas. The content of total-phosphate and $\mathrm{NH}_{4}{ }^{+}-\mathrm{N}$ in the sediments of eelgrass beds were lower than the sediments of the unvegetated area, while the bacterial abundance and diversity in eelgrass bed were greater than that of unvegetated area. The most abundant bacteria found in sediments were Proteobacteria, Bacteroidetes, Planctomycetes and Acidobacteria, while the bacterial community structures were significantly different between the two areas. The changes found in the environmental factors and microbial communities were mainly attributed to the presence of $Z$. marina. This study may provide further understanding of the effects of $Z$. marina, which may be vital to the regulation of the marine environment.
\end{abstract}

Keywords: Zostera marina, environmental factors, microbial communities, marine sediments, marine environment

\section{Introduction}

Seagrasses are a unique group of plants that comprise 60 monocotyledonous angiosperm species (Hemminga and Duarte, 2002) that grow in coastal sediments in shallow coastal zones (Fonseca, 1998; Lebreton et al., 2012). Zostera marina is one of the most common seagrasses and distributed mainly in temperate regions of the northern hemispheres (Short et al., 2007; Zhou et al., 2015). Eelgrass meadow can provide a valuable habitat and food source for many invertebrates and fishes (Gillanders, 2006).

In recent years, many studies on Z. marina have focused on its biological processes that are related to photosynthesis, nitrogen fixation and restoration (Goodman et al., 1995; McGlathery et al., 1998; Marion, 2010). Eelgrass link sediment and nutrient cycles providing several vital coastal ecosystem functions (Harlin et al., 1981), so their protection and restoration are important. Many bacterial species found in the sediments of eelgrass bed are absent in sediment habitats outside of eelgrass bed (Campbell et al., 1990; Shieh et al., 1997). Several studies showed that bacteria inhabit the roots of the eelgrasses (Kuo et al., 1981; Kurtz et al., 2003; Küsel et al., 1999; Nielsen et al., 1999) and may form synergistic relationships. Eelgrass can excrete amino acids and sugars from their roots, thereby create suitable niches for a wide variety of microorganisms in the rhizosphere (Lee et al., 2000; Holmer et al., 2001; Jensen et al., 2005). Double 
gradient denaturing gradient gel electrophoresis (DG-DGGE) was used to investigate several factors' impact on bacterial community diversity, and the results suggests that vegetation and season exert stronger controls on microbial community structure (James et al., 2006). Jensen et al., found that eelgrass can affect microbial processes in the rhizoplane via the excretion of amino acids and sugars. Significant differences in the bacterial communities associated with the roots and the bulk sediment associated with Z. marina have been found (Jensen et al., 2007), and the presence of roots could favour the growth of particular bacteria. Few studies to date have examined the effects of the eelgrass meadow on the environmental factors and bacterial communities.

In this study, we used a variety of methods to measure the environmental factors in sediments collected from eelgrass meadow and unvegetated area. We then characterized the richness, diversity, similarity, and composition of the microbial communities. In addition, root-specific bacteria were also analysed.

\section{Materials and methods}

\section{Study area and sampling}

Shuangdao Bay is located in Weihai, which lies within the Shandong Peninsula in northern China $\left(\mathrm{N} 37^{\circ} 28.5^{\prime}-37^{\circ} 29.2^{\prime}\right.$, E12 $\left.1^{\circ} 57.5^{\prime}-122^{\circ} 58.5^{\prime}\right)$. The sample S1 (N37 $29.087^{\prime}$, E12 $\left.1^{\circ} 58.267^{\prime}\right)$ was collected from the sediments in eelgrass meadow, while sample S2 (N37 $\left.29.045^{\prime}, \mathrm{E} 121^{\circ} 58.286^{\prime}\right)$ was collected from the sediments in adjacent unvegetated area (Fig. 1). S0, S40, and S80 were collected from the sediments of a single plant. The sediment taken from the root of $Z$. marina was designated S0 (N37 $\left.29.073^{\prime}, \mathrm{E} 121^{\circ} 58.306^{\prime}\right)$, and the sediments taken from 40 and $80 \mathrm{~cm}$ away from the root were designated as S40 and S80, respectively. The S40 and S80 samples are a mixture of four samples taken from the circumference of the sampling zone. Samples were collected in April 2015.

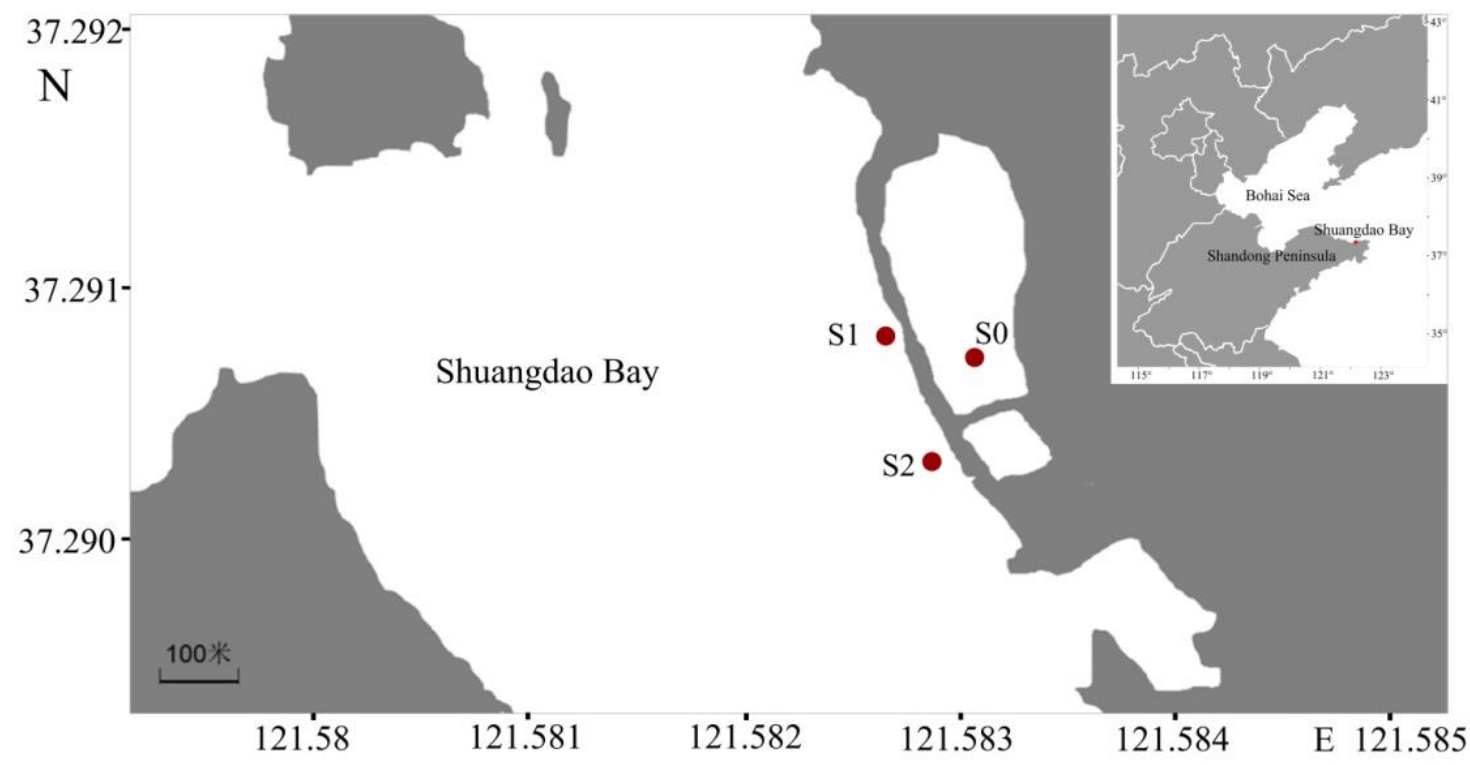

Figure 1. Sampling area in Shuangdao Bay, Shandong Peninsula, China. Sediments were sampled in eelgrass beds (S1) and in adjacent unvegetated area (S2) 
In each sampling location, a composite sediment sample was collected at a depth of approximately $0-10 \mathrm{~cm}$ using a bottom sampler. Each fresh composite sample was subdivided into two subsamples, one of which was stored at $-80^{\circ} \mathrm{C}$ prior to bacterial $16 \mathrm{~S}$ ribosomal ribonucleic acid (rRNA) gene sequencing, while the other was freezedried and tested to determine the levels of elemental factors that included salinity and nutrition factors such as sediment organic matter (SOM), total-nitrogen (TN), totalphosphate (TP), $\mathrm{NO}_{3}{ }^{-}, \mathrm{NO}_{2}{ }^{-}, \mathrm{NH}_{4}{ }^{+}, \mathrm{PO}_{4}{ }^{3-}$ and water-soluble sulfide (WS).

\section{Determination of environmental parameters in sediment}

The contents of SOM and WS were determined by using the muffle furnace heating methodand $\mathrm{BaSO}_{4}$ turbidimetry ( $\mathrm{Lv}$ et al., 2018), respectively; three replicates were performed for each measurement. The TN/TP extract solution was obtained using a simultaneous preparation method ( $\mathrm{Li}$ et al., 2007) and the contents of TN and TP were determined by using zinc cadmium reduction and the phosphomolybdenum blue method, which utilizes the reduction of ascorbic acid for specific ions according to the oceanographic survey GB17378.5-2007, respectively. $\mathrm{NO}_{3}{ }^{-}$was determined using zinc cadmium reduction, while $\mathrm{NH}_{4}{ }^{+}$was detected using the indophenol blue method described in GB17378.5-2007. One-way ANOVA (Wolfram Mathematic 11.3) was used and the LSD-t tests were performed to compare TN, TP, WS, SOM, $\mathrm{NH}_{4}{ }^{+}$and $\mathrm{NO}_{3}{ }^{-}$between different samples. Differences were deemed significant at $\mathrm{P}<0.05$ and extremely significant at $\mathrm{P}<0.01$. Values are means $\pm \mathrm{SD}(\mathrm{n}=3)$.

\section{DNA extraction, clone library construction, PCR amplification and high-throughput sequencing}

The PowerSoil DNA Isolation Kit (TineGene Limited Company, Shanghai) was used to extract the genomic DNA. The DNA library was established using a two-step PCR amplification method, and the sequencing was conducted on an Illumina Miseq 16S rDNA system. The PCR primer sequences used to amplify the V4-V5 region within the bacterial DNA are shown in Table 1. The 16S rDNA sequences of S1 and S2 have been deposited in the NCBI Sequence Read Archive under accession number PRJNA506488. The 16S rDNA sequences of S0, S40 and S80 have been deposited in the NCBI Sequence Read Archive under accession number SRP158072.

Table 1. The PCR primers sequences for amplifying bacterial DNA

\begin{tabular}{|c|c|c|}
\hline \multicolumn{2}{|c|}{ Primer name } & Sequence (5'-3') \\
\hline \multirow{2}{*}{$\begin{array}{c}\text { 16SrDNA } \\
\text { (1st amplification) }\end{array}$} & $515 \mathrm{~F}$ & $\begin{array}{c}\text { AATGATACGGCGACCACCGAGATCTACACNNNNNNNNTCTTTCCCTAC } \\
\text { ACGACGCTCTTCCGATCTGTGCCAGCMGCCGCGGTAA }\end{array}$ \\
\hline & $926 \mathrm{R}$ & $\begin{array}{l}\text { CAAGCAGAAGACGGCATACGAGATNNNNNNNNGTGACTGGAGTTCCTT } \\
\text { GGCACCCGAGAATTCCACCGTCAATTCMTTTGAGTTT }\end{array}$ \\
\hline \multirow{4}{*}{$\begin{array}{c}\text { 16SrDNA } \\
\text { (2nd amplification) }\end{array}$} & $\begin{array}{c}515 \mathrm{~F} \\
\text { (Inner) }\end{array}$ & TTCCCTACACGACGCTCTTCCGATCTGTGCCAGCMGCCGCGGTAA \\
\hline & $\begin{array}{l}515 \mathrm{~F} \\
\text { (Outer) }\end{array}$ & $\begin{array}{l}\text { AATGATACGGCGACCACCGAGATCTACACNNNNNNNNTCTTTCCCTAC } \\
\text { ACGACGCTC }\end{array}$ \\
\hline & $\begin{array}{c}926 \mathrm{R} \\
\text { (Inner) }\end{array}$ & GAGTTCCTTGGCACCCGAGAATTCCACCGTCAATTCMTTTGAGTTT \\
\hline & $\begin{array}{l}926 \mathrm{R} \\
\text { (Outer) }\end{array}$ & $\begin{array}{l}\text { CAAGCAGAAGACGGCATACGAGATNNNNNNNNGTGACTGGAGTTCCTT } \\
\text { GGCACCCGAGA }\end{array}$ \\
\hline
\end{tabular}




\section{Data analyses}

Paired-end reads were assigned to each sample based on their unique barcode and were truncated by cutting off the bar code and primer sequence. Split sequences for each sample were merged using FLASH V1.2.7 (Magoc and Salzberg, 2011), and the splicing sequences were called raw tags. Quality filtering on the rawtags was performed under specific filtering conditions to obtain the high-quality clean tags according to the QIIME quality-controlled process (Caporaso et al., 2011). The tags were compared with the reference database using UCHIME algorithm (Edgar et al., 2011; UCHIME, 2011) to detect chimera sequences, and then the chimera sequences were removed, finally obtaining the effective tags. Using the USEARCH and Perl scripts, the sequences retained were analyzed following the UPARSE pipeline to generate an operational taxonomic unit (OTU) table and pick representative sequences (Edgar, 2013). The sequences with a length shorter than $200 \mathrm{bp}$ and singletons were removed. The retained sequences were were aligned with the 16S rDNA sequences using Silva 119 (http://www.arb-silva.de/) in order to annotate the species based on $97 \%$ sequence similarity using the average neighbour method. Taxonomical assignments of OTUs were executed using MOTHUR 1.33.3. OTU abundance information was normalized using a standard sequence number corresponding to the sample with the least sequences. Rarefaction analysis was performed to compare the relative levels of OTU richness across all sediment samples at an OTU cutoff of 0.03 (Xu et al., 2017). Principal components analysis (PCA) of the PCORD5 is used to examine the relationship between the microbial community (phyla) and environmental factors. All data are tested for normal distributions before ANOVA. Figures are prepared by PCORD5.

\section{Results}

\section{Determination of environmental factors in sediment}

Compared with S2, the contents of TP (LSD-t $=113.12, \mathrm{p}<0.01)$ and $\mathrm{NH}_{4}{ }^{+}(\mathrm{LSD}-$ $\mathrm{t}=7.41, \mathrm{p}<0.01)$ in $\mathrm{S} 1$ were significantly reduced, while the contents of other factors have no significant differences (Fig. 2). To explore whether these differences were caused by the presence of eelgrass, we examined these environmental factors in the sediment near its roots (S0), as well as $40 \mathrm{~cm}$ (S40) and $80 \mathrm{~cm}$ (S80) from the roots. The contents of $\mathrm{NH}_{4}{ }^{+}(\mathrm{LSD}-\mathrm{t}=0.007825, \mathrm{p}<0.05)$ and TP $(\mathrm{LSD}-\mathrm{t}=0.02093, \mathrm{p}<0.05)$ in S0 were lower than that of S40 and S80 (Fig. 3). In conclusion, the sediment in eelgrass meadow contains lower levels of TP and $\mathrm{NH}_{4}{ }^{+}$than that of unvegetaed area.

\section{Microorganism richness and diversity}

After processing, 33424 and 27009 high-quality sequences were obtained from S1 and S2, respectively. A total of 9640 OTUs were obtained for the samples at 3\% dissimilarity (Table 2). The abundance indices (Chao and Ace indexes) of S1 were both higher than that of sample S2, while the diversity indices (Shannon and Simpson indexes) were lower than that of sample S2. These results suggested that the bacterial abundance and diversity in the sediment of eelgrass meadow were greater than that unvegetated area. In the same way, we measured the microorganism richness and diversity in S0, S40 and S80. After processing, 72720, 53733 and 25842 high-quality sequences were obtained from these samples, and a total of 15232 OTUs were obtained 
(Table 2). As shown in Table 2, the bacteria diversity and richness in the sediment near the roots ( $\mathrm{S} 0$ and $\mathrm{S} 40$ ) were greater than that of sediment far from the roots (S80).
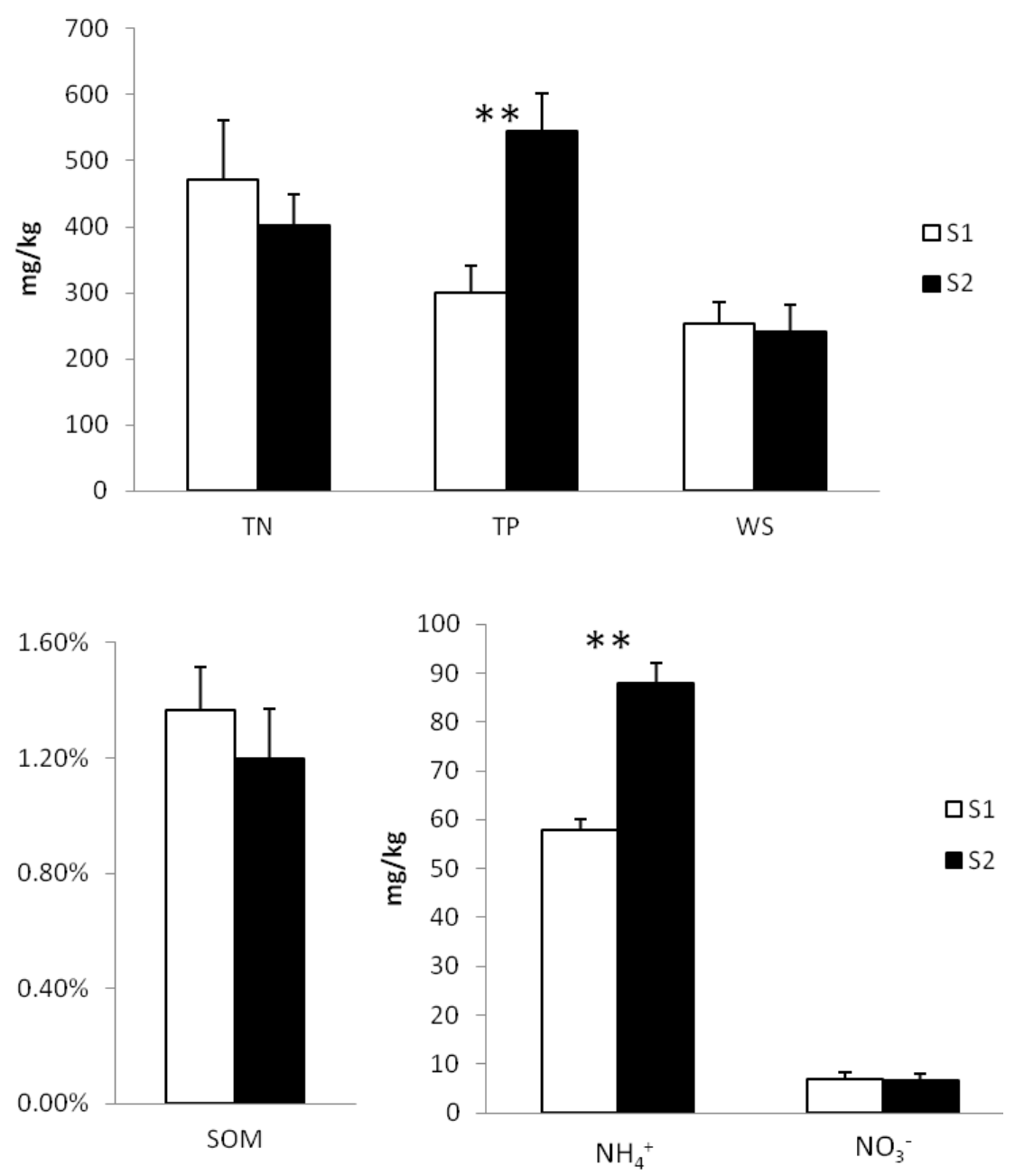

Figure 2. The change of environmental factors in the sediments. Values are means $\pm S D$ $(n=3) . * P<0.01$. TN: total-nitrogen; TP: total-phosphate; WS: water-soluble sulfide; SOM: sediment organic matter
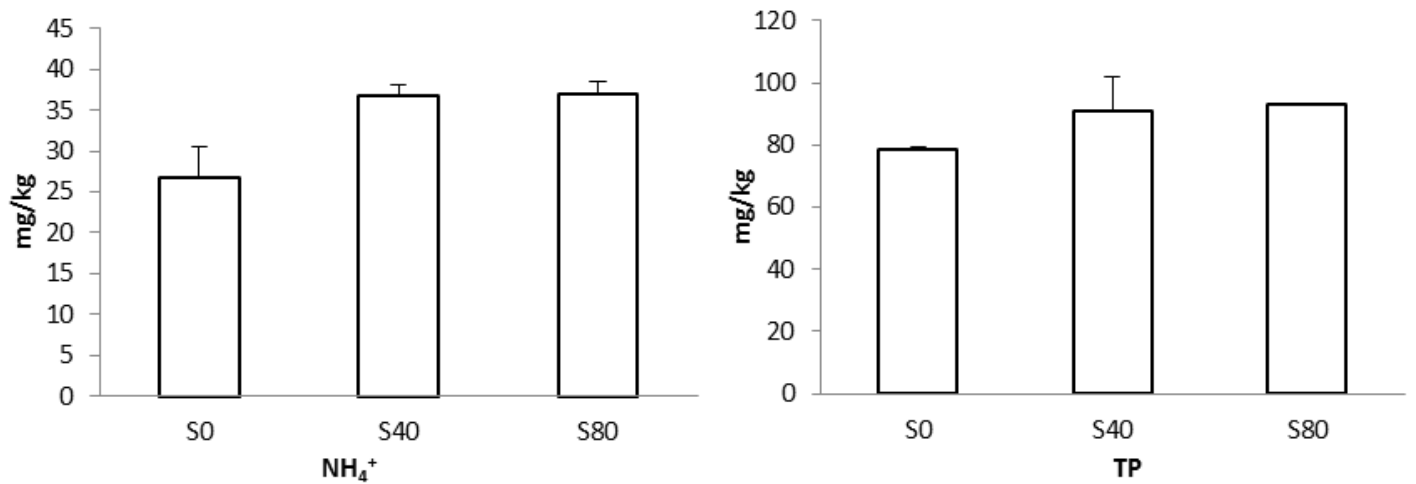

Figure 3. The contents of $\mathrm{NH}_{4}{ }^{+}$and TP in the SO, S40 and S80. Values are means $\pm S D(n=3)$. $* P<0.05$. TP: total-phosphate 
Table 2. The community richness and diversity in different samples

\begin{tabular}{c|c|c|c|c|c|c}
\hline Sample & OTU numbers & Coverage & Chao index & Ace index & Shannon index & Simpson index \\
\hline S1 & 5260 & 84.3 & 11668 & 24097 & 7.05 & 0.0042 \\
S2 & 4380 & 85.8 & 10315 & 16090 & 7.03 & 0.0036 \\
S0 & 5735 & 92.1 & 11957.1 & 16241.4 & 6.9 & 0.0049 \\
S40 & 5455 & 88.3 & 12717.0 & 19374.8 & 7.0 & 0.0046 \\
S80 & 4042 & 90.1 & 9225.0 & 14475.2 & 6.5 & 0.0067 \\
\hline
\end{tabular}

\section{Comparison of microbial communities among different samples}

To assess the variation in the microbial communities, the compositions of taxa at the phyla and class levels are represented in a pie chart (Figs. 4 and 5). A significant difference in bacterial community was found between eelgrass beds and adjacent unvegetated area. At the level of phyla (Fig. 4), the most abundant phylum represented within each sample was Proteobacteria, which comprised $48 \%$ and $53 \%$ of the reads from $\mathrm{S} 1$ and $\mathrm{S} 2$.

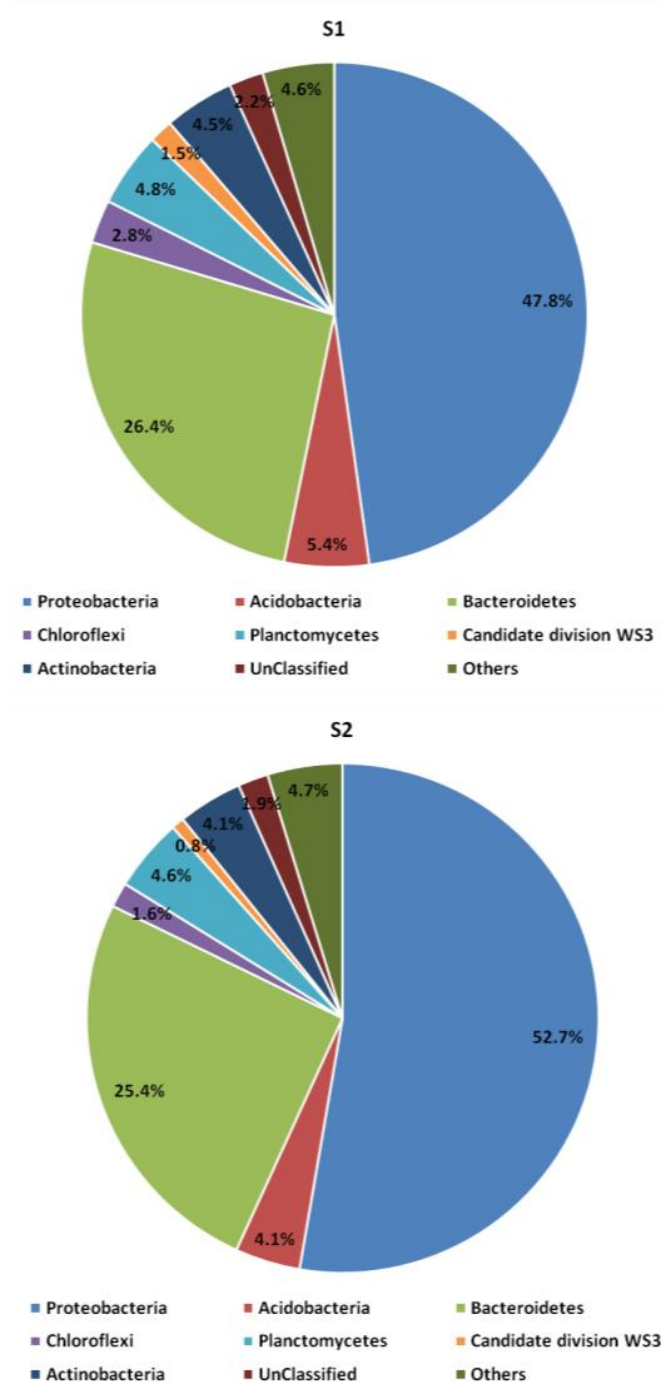

Figure 4. The diagram for different samples's microbial communities at phylum level 
The relative abundances of Proteobacteria, Gemmatimonadetes, Cyanobacteria and Chlamydiae were higher in the sediment of eelgrass meadow, while the relative abundances of Bacteroidetes, Firmicutes, Deferribacteres, Planctomycetes and Chlorobi were higher $(\mathrm{P}<0.05)$ in the sediment of adjacent unvegetated area. At the level of class (Fig. 5), the relative abundance of Gemmaproteobacteria was higher in the presence of eelgrass, while the relative abundances of Alphaproteobacteria, Flavobacteriia, Sphingobacteriia and Planctomycetacia were higher $(\mathrm{P}<0.05)$ in the absence of eelgrass.

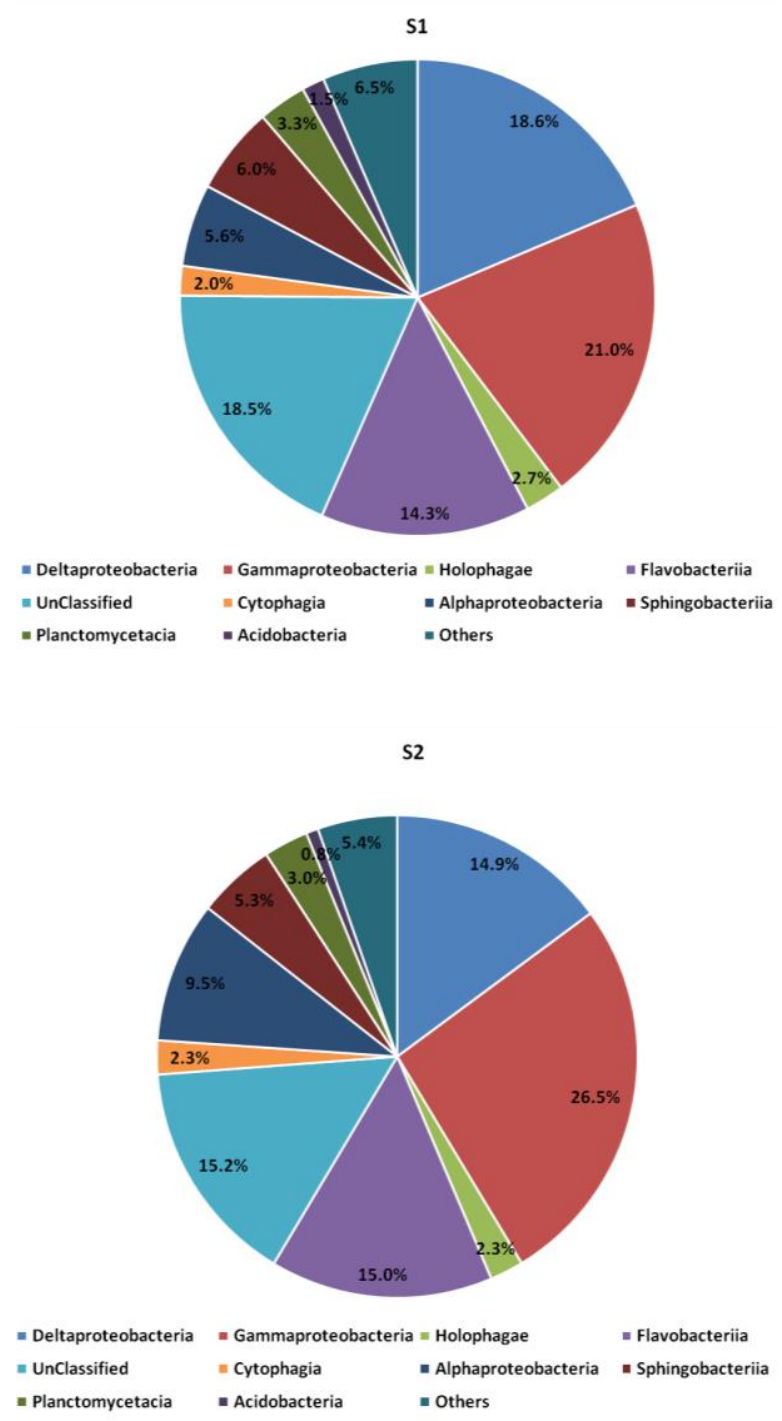

Figure 5. The diagram for different samples's microbial communities at class level

\section{Microbial community and environmental conditions}

Sediment properties are listed in Figures 2 and 3. The sediment in eelgrass meadow had much lower TP and $\mathrm{NH}_{4}{ }^{+}$contents. The PCA analysis showed that PC1 and PC2 explained $56.246 \%$ and $18.277 \%$ of the bacterial phyla, respectively. The changes of microbial community composition in $\mathrm{S} 1$ and $\mathrm{S} 2$ were mainly attributed to $\mathrm{NH}_{4}{ }^{+}, \mathrm{NO}_{3}{ }^{-}$ and TN (Fig. 6). 


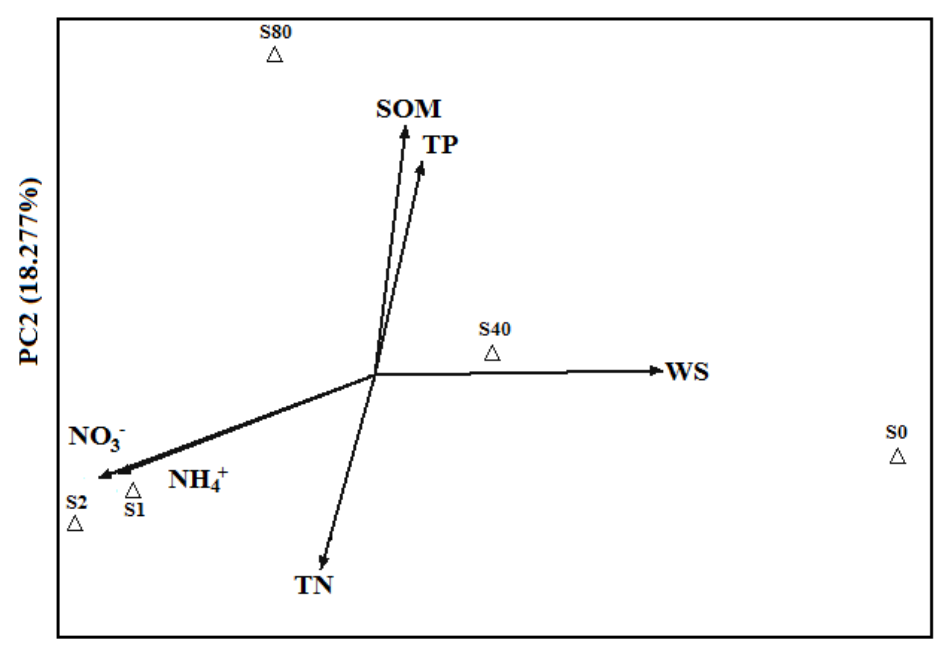

PC1 (56.246\%)

Figure 6. Principal components analysis (PCA) of the microbial community composition and sediment properties on the basis of the relative abundance of bacterial phyla

\section{Root-specific bacteria}

To obtain the root-specific bacteria of eelgrass, we analysed the OTUs specifically detected in S0. The results showed that there were 2654 unique OTUs detected within the roots of $Z$. marina, and the OTU size was 3464. Among these, 601 OTUs were identifiable at the family level, 302 at the genus level, and 11 at the species level. At the family level, the identified bacteria were Alicyclobacillaceae, Anaerolineaceae, Desulfobacteraceae, Desulfobulbaceae, Flavobacteriaceae, Planctomycetaceae and Spirochaetaceae. At the genus level, the identified bacteria were Coxiella, Desulfococcus, Desulfobulbus, Acidiferrobacter, Geobacter, Sulfurovum, Rhodopirellula and Spirochete. The eleven identified species were Bacillus hwajinpoensis, Bacillus algicola, Brevundimonas bullata, Brevundimonas vesicularis, Paenibacillus provencensis, Roseiovarius aestuarii, Labrenzia marina, Lewinella nigricans, Sphingomonas paucimobilis, Ruditapes philippinarum, and Stenotrophomonas acidaminiphila.

\section{Discussion}

\section{Influence on environmental factors}

The sediment in eelgrass meadow contains low levels of TP and $\mathrm{NH}_{4}{ }^{+}$(Figs. 2 and $3)$. In this study, the content of $\mathrm{NH}_{4}{ }^{+}$was significantly lower in eelgrass meadow which may be due to the vigorous ammonium absorption process in the roots (Hemminga et al., 1994). The contents of the other environmental factors such as organic matter have no significant difference in eelgrass meadow and unvegetated area which is consistent with previous research (Xu et al., 2016). From the above results, we speculate that nitrogen metabolism and phosphorus metabolism in the sediments inside eelgrass meadow are more vigorous than those outside eelgrass meadow, while there is no significant difference in carbon metabolism and sulfur metabolism. These environmental factors are considered to have been influenced by the presence of eelgrass, then influence the growth of particular bacteria. 


\section{Variation in the bacterial community and ecological functioning}

The coverage index for all of the samples in this study was estimated to be between $84.3 \%$ and $92.1 \%$, which indicated that the results of the high-throughput sequencing most likely encompass most of the microbial organisms in the sediment. The richness and diversity analysis indicated that the bacterial abundance and diversity in eelgrass meadow were greater than in the unvegetated areas (Table 2), which may be related to the metabolic cycle or root exudates of Z. marina.

Proteobacteria is the most abundant phylum of bacteria in many coastal areas ( $\mathrm{Hu}$ et al., 2014; Li et al., 2016). In the present study, this phenomenon is laso observed, and the dominance of Proteobacteria does not change in different samples (Fig. 4). In this study, the microbial community structures were analyzed on the basis of two approaches: eelgrass meadow analysis (Figs. 4 and 5) and single eelgrass analysis (Fig. 7). The two different approaches did not return similar result. The results suggested that the bacteria communities in sediment were complex. The results indicate that the first approach is more representative of the effect of eelgrass on microbial communities in sediments, as the effects of individual plant is limited.

A

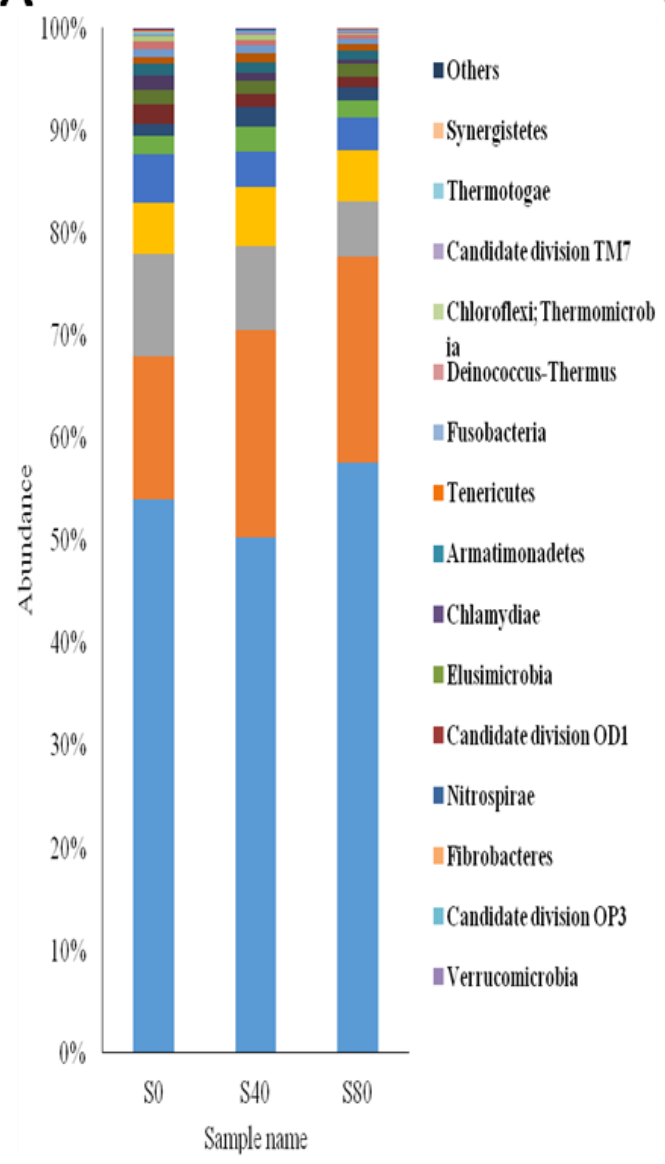

B

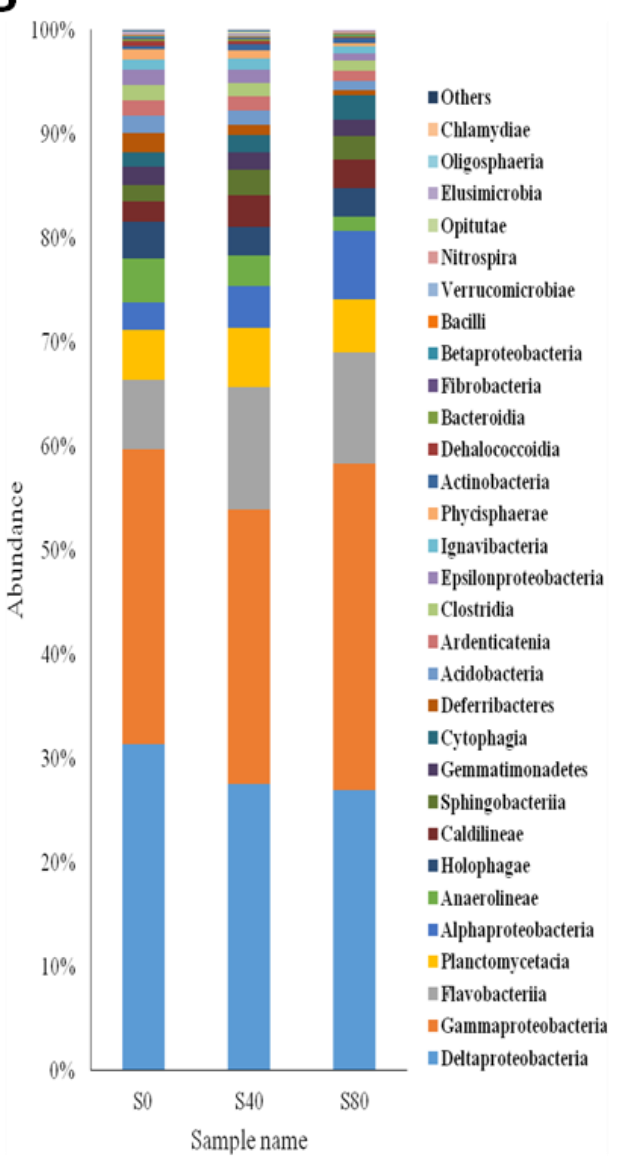

Figure 7. The diagram for different samples' microbial communities at phylum level (A) and class level (B)

Nutrient loading was reported to regulate the shifts in microbial structure and diversity in sediment along the river (Wang et al., 2018). Previous studies reported that 
microbial biomass in saline environments was increased by an addition of easily decomposable substrate (Yan and Marschner, 2012), and TN is the main factor increasing the microbial biomass ( $\mathrm{Li}$ et al., 2016). In this study, the $\mathrm{S} 1$ (in eelgrass meadow) and S2 (in unvegetated area) sites had apparently different bacterial phylum structure, which was found to be attributed to $\mathrm{NH}_{4}{ }^{+}, \mathrm{NO}_{3}{ }^{-}$and $\mathrm{TN}$ (Fig. 6). On the basis of the environmental properties results, we believe that $\mathrm{NH}_{4}{ }^{+}$content in sediment influence the microbial community structure of eelgrass meadow.

\section{Root-specific microorganisms}

Root-specific microorganisms were analyzed through single eelgrass analysis. The results showed that there were 2654 unique OTUs detected within the roots of $Z$. marina, while there were 5735 OTUs detected. The result indicated that the microbial community structure and diversity in the area near the roots of eelgrass are significantly different from the surrounding environment. There abundance of Rhodopirellula in habitats with eelgrass was lower than that of unvegetated area. As a kind of Planctomycetes, Rhodopirellula has an anaerobic ammonium oxidation function (Wecker et al., 2010). It is speculated that the nitrogen cycle in sediments with eelgrass is more vigorous, and the conversion of ammonium is more rapid, which is also consistent with the ammonium content of the sample S1 below the sample S2 (Fig. 2). The microorganisms specifically detected in the roots of eelgrass may be closely related to their growth, which reflect the influence of eelgrass meadow on environmental factors and microbial community.

Based on the current and previous studies, we proposed that microbial community composition was closely related to environmental factors which may be influenced by the presence of eelgrass. However, more studies are needed on whether the sediments' microbial community compositions in different areas have the same trend.

\section{Conclusions}

Based on the measurements of the environmental factors, the sediments in eelgrass meadow have low levels of $\mathrm{NH}_{4}{ }^{+}$and TP. The abundance and diversity of the microorganisms in the sediment with eelgrass were greater than in the sediment without eelgrass. In addition, significantly differences were observed in the microbial community composition between eelgrass meadow and unvegetated aera. Therefore, we speculate that the changes in the structure of the microbial community in the sediments with eelgrass are closely related to the vigorous $\mathrm{N}$ and $\mathrm{P}$ metabolism.

Acknowledgements. We thank Weiteng Mao and Zhaoyang Hua for sediment sampling, Haonan Wu for statistical analysis. This research was funded by the Shandong Province Natural Science Foundation (Grant No. ZR2014DP006) and Weihai Ocean Institute Project (Grant No. 1070413421424).

\section{REFERENCES}

[1] Campbell, R., Greaves, M. P. (1990): Anatomy and Community Structure of the Rhizosphere. - In: Lynch, J. M. (ed.) The Rhizosphere. John Wiley \& Sons, Chichester, pp. 11-34. 
[2] Caporaso, J. G., Lauber, C. L., Walters, W. A., Berg-Lyons, D., Lozupone, C. A. Turnbaugh, P. J., Fierer, N., Knight, R. (2011): Global patterns of 16S rRNA diversity at a depth of millions of sequences per sample. - Proceedings of the National Academy of Sciences of the United States of America 108(25): 4516-4522. DOI: 10.1073/pnas.1000080107.

[3] Edgar, R. C. (2013): UPARSE: Highly accurate OTU sequences from microbial amplicon reads. - Nature Methods 10(10): 996-998. DOI: 10.1038/NMETH.2604.

[4] Edgar, R. C., Haas, B. J., Clemente, J. C., Quince, C., Knight, R. (2011): UCHIME improves sensitivity and speed of chimera detection. - Bioinformatics 27(16): 2194-2200. DOI: 10.1093/bioinformatics/btr381.

[5] Fonseca, M., Julius, B. E., Kenworthy, W. J. (1998): Integrating biology and economics in seagrass restoration: how much is enough and why. - NOAA Conf. on Goal Setting and Success Criteria for Coastal Habitat Restoration, Charleston, SC, pp. 12-14. DOI: 10.1016/S0925-8574(00)00078-1.

[6] Gillanders, B. M. (2006): Seagrasses, Fish and Fisheries. - In: Larkum, A. D. W., Orth, R. J., Duarte, C. M. (eds.) Seagrasses: Biology, Ecology and Conservation. Springer, Dordrecht, pp. 503-536. DOI: 10.1007/978-1-4020-2983-7.

[7] Goodman, J. M., Dennison, W. C. (1995): Photosynthetic responses of eelgrass (Zostera marina L.) to light and sediment sulfide in a shallow barrier island lagoon. - Aquatic Botany 50(1): 37-47. DOI: 10.1016/0304-3770(94)00444-Q.

[8] Harlin, M. M., Thorne-Miller, B. (1981): Nutrient enrichment of seagrass beds in a Rhode Island coastal lagoon. - Mar Biol 65(3): 221-229. DOI: 10.1007/BF00397115.

[9] Hemminga, M. A., Duarte, C. M. (2002): Seagrass ecology. - Limnology and Oceanography 47(2): 611-611. DOI: 10.4319/lo.2002.47.2.0611.

[10] Hemminga, M. A., Koutstaal, B. P., Soelen, J. V., Merks, A. G. A. (1994): The nitrogen supply to intertidal eelgrass (Zostera marina). - Marine Biology 118(2): 223-227. DOI: 10.1007/ BF00349788.

[11] Holmer, M., Andersen, F. O., Nielsen, S. L., Boschker, H. T. S. (2001): The importance of mineralization based on sulfate reduction for nutrient regeneration in tropical seagrass sediments. - Aquat Bot 71(1): 1-17. DOI: 10.1016/s0304-3770(01)00170-X.

[12] Hu, Y., Wang, L., Tang, Y., Li, Y., Chen, J., Xi, X. et al. (2014): Variability in soil microbial community and activity between coastal and riparian wetlands in the Yangtze River estuary - potential impacts on carbon sequestration. - Soil Biology and Biochemistry 70: 221-228. DOI: 10.1016/j.soilbio.2013.12.025.

[13] James, J. B., Sherman, T. D., Devereux, R. (2006): Analysis of bacterial communities in seagrass bed sediments by double-gradient denaturing gradient gel electrophoresis of PCR-amplified 16S rRNA genes. - Microb Ecol 52(4): 655-661. DOI: 10.1007/s00248006-9075-3.

[14] Jensen, S. I., Kuhl, M., Glud, R. N., Jorgensen, L. B., Prieme, A. (2005): Oxic microzones and radial oxygen loss from roots of Zostera marina. - Mar Ecol Prog Ser 293: 49-58.

[15] Jensen, S. I., Kuhl, M., Prieme, A. (2007): Different bacterial communities associated with the roots and bulk sediment of the seagrass Zostera marina. - FEMS MicrobiolEcol 62: 108-117. DOI: 10.1111/j.1574-6941.2007.00373.x.

[16] Kuo, J., McComb, A. J., Cambridge, M. L. (1981): Ultrastructure of the seagrass rhizosphere. - New Phytol 89(1): 139-143. DOI: 10.1111/j.1469-8137.1981.tb04756.x.

[17] Kurtz, J. C., Yates, D. F., Macauley, J. M., Quarles, R. L., Genthner, F. L., Chancy, C. A., Devereux, R. (2003): Effects of light reduction on growth of the submerged macrophyte Vallisneria Americana and the community of heterotrophic root-associated bacterial. - J Exp Mar Biol Ecol 291(2): 199-218. DOI: 10.1016/S0022-0981(03)001205. 
[18] Küsel, K., Pinkart, H. C., Drake, H. L., Devereux, R. (1999): Acetogenic and sulfatereducing bacteria inhabiting the rhizoplane and deep cortex cells of the sea grass Halodule wrightii. - Appl Environ Microbiol 65(11): 5117-5123.

[19] Lebreton, B., Richard, P., Galois, R., Radenac, G., Brahmia, A., Colli, G., Grouazel, M., André, C., Guillou, G., Blanchard, G. F. (2012): Food sources used bysediment meiofauna in an intertidal Zostera noltii seagrass bed: a seasonalstable isotope study. Mar Biol 159(7): 1537-1550. DOI: 10.1007/s00227-012-1940-7.

[20] Lee, K. S., Dunton, K. H. (2000): Diurnal changes in pore water sulfide concentrations in the seagrass Thalassia testudinum beds: the effects of seagrasses on sulfide dynamics. - J Exp Mar Biol Ecol 255(2): 201-214. DOI: 10.1016/S0022-0981(00)00300-2.

[21] Li, X. G., Song, J. M., Li, N., Niu, L. F., Yuan, H. M., Dai. J. C. (2007): Simultaneous determination of nitrogen and phosphorus in sediments and its application in Jiaozhou Bay. - Rock and Mineral Analysis 26(2): 87-92 (in Chinese). DOI: 10.1631/jzus.2007.B0900.

[22] Li, Y. Q., Wang, Y. D., Xu, S. Q., Hu, B. B., Wang, Z. L. (2016): Effects of mariculture and solar-salt production on sediment microbial community structure in a coastal wetland. - Journal of Coastal Research 33(3): 573-582. DOI: 10.2112/JCOASTRES-D16-00093.1.

[23] Lv, X., Yu, P., Mao, W., Li, Y. (2018): Vertical variations in bacterial community composition and environmental factors in the culture pond sediment of sea cucumber Apostichopus japonicus. - Journal of Coastal Research 84(sp1): 69-76. DOI: 10.2112/SI84-010.1.

[24] Magoc, T., Salzberg, S. L. (2011): FLASH: Fast length adjustment of short reads to improve genome assemblies. - Bioinformatics 27(21): 2957-2963. DOI: 10.1093/bioinformatics/btr507.

[25] Marion, S., Rao, R. J. (2010): Innovative techniques for large-scale seagrass restoration using Zostera marina (eelgrass) Seeds. - Restoration Ecology 18(4): 514-526. DOI: 10.1111/j.1526-100X.2010.00692.x.

[26] McGlathery, K. J., Risgaard-Petersen, N., Christensen, P. B. (1998): Temporal and spatial variation in nitrogen fixation activity in the eelgrass Zostera marina rhizosphere. Marine Ecology Progress Series 168: 245-258. DOI: 10.3354/meps168245.

[27] Nielsen, J. T., Liesack, W., Finster, K. (1999): Desulfovibrio zosterae sp. nov., a new sulfate reducer isolated from surface-sterilized roots of the seagrass Zostera marina. - Int J Syst Bacteriol 2(2): 859-865. DOI: 10.1099/00207713-49-2-859.

[28] Shieh, W. Y., Yang, J. T. (1997): Denitrification in the rhizosphere of the two seagrasses Thalassia hemprichii (Ehrenb.) Aschers and Halodule uninervis (Forsk.) Aschers. - J Exp Mar Biol Ecol 218(2): 229-241. DOI: 10.1016/s0022-0981(97)00076-2.

[29] Short, F., Carruthers, T., Dennison, W., Waycott, M. (2007): Global seagrass distribution and diversity: a bioregional model. - J ExpMar Biol Ecol 350: 3-20. DOI: 10.1016/j.jembe.2007.06.012.

[30] UCHIME (2011): http://drive5.com/uchime/uchime_download.html.

[31] Wang, Y., Wang, Z. L. (2018): Shifts of sediment microbial community structure along a salinized and degraded river continuum. - Journal of Coastal Research 342: 443-450.

[32] Wecker, P., Klockow, C., Schüler, Margarete, Dabin, Jérôme, Michel, G., Glöckner, Frank, O. (2010): Life cycle analysis of the model organism rhodopirellula baltica sh 1t by transcriptome studies. - Microbial Biotechnology 3(5): 583-594. DOI: 10.1111/j.1751-7915.2010.00183.x.

[33] Xu, Q., Liu, B., Zhou, Y. (2016): Does the eelgrass meadow influence the macrobenthic community structure in swan lake, northern China? - Marine Biodiversity 1-8. DOI: 10.1007/s12526-016-0601-3.

[34] Xu, S., Wang, Y., Guo, C., Zhang, Z., Shang, Y., Chen, Q., Wang, Z.-L. (2017): Comparison of microbial community composition and diversity in native coastal wetlands 
and wetlands that have undergone long-term agricultural reclamation. - Wetlands 37: 99108. DOI: 10.1007/s13157-016-0843-7.

[35] Yan, N., Marschner, P. (2012): Response of microbial activity and biomass to increasing salinity depends on the final salinity, not the original salinity. - Soil Biology \& Biochemistry 53: 50-55.

[36] Zhou, Y., Liu, X., Liu, B., Liu, P., Wang, F., Zhang, X., Yang, H. (2015): Unusual pattern in characteristics of the eelgrass Zostera marina L. in a shallow lagoon (Swan Lake), North China: implications on the importance of seagrass conservation. - Aquat Bot 120: 178-184. DOI: 10.1016/j.aquabot.2014.05.014. 